\title{
Study of Forces Acting on Excavator Bucket While Digging
}

Khedkar $\mathbf{Y}^{1}$, Dey $\mathbf{T}^{1^{*}}$ and Padasalagi $\mathbf{Y}^{2}$

${ }^{1}$ Department of Mechanical Engineering, DY Patil College of Engineering, Akurdi, Pune, India 2India Design Center, JCB India, Pune, India

\begin{abstract}
Excavator is a construction machine which is widely used for various constructions, mining and agricultural work. For easy excavating of tool into soil it's necessary that the digging force offered by tool must be greater than the resistive force offered by soil. Design of excavator bucket is a challenging work because it's a first part which comes in contact with soil. Various forces are acting on the bucket which resists the motion of bucket into the soil. This paper focuses on factor affecting the resistive force, also the resistive force offered by stiff soil to the bucket has been designed, and Digging forces are calculated as per SAE standard, Effect of various parameters on resistive force has been discussed for horizontal and uneven digging condition.
\end{abstract}

Keywords: Digging modes; Digging forces; Penetration resistance; Separation resistance; Digging force; Static force analysis

\section{Introduction}

Excavator machines are commonly used for infrastructure development and in mining industries. This is an industrial vehicle consisting of a linkage arrangement; cab mounted on tracked cabin for the operator wheeled or tracked system for movement. Hydraulic system is used for operation of the mechanism. Excavation has major importance in mining, construction and general earthworks. Hydraulic cylinders apply forces to boom, arm and the bucket to actuate the mechanism. Depending on the mechanism position, working pressure and diameter of the hydraulic cylinders, the amount of excavation force changes [1]. Boom, arm and bucket cylinders are used for movement of the linkages out of which arm and boom cylinder are used for digging purpose. A variety of Buckets are used to improve the Productivity, Digging, better material retention and clean release of material. The shape of the bucket is the main aspect which is accountable for resistive force and the digging force. More optimized shape of the bucket less is the resistive force. Excavator is digging in different soil conditions such as lose soil, stiff soil, granite etc. for every condition there are different soil resistance. As the usage of excavator in day to day life is increasing for many purposes but the applicable site is not inspected properly due urgency of work by the owner or the contractor due to which improper handling of it leads to damage of the ground engaging tool i.e. bucket. The bucket of the excavator is main contacting part of it which comes in contact with the soil and rocks while doing excavation at various sites. So in this case sometimes the bucket gets damage due to some improper handling by the operators, which leads to the loss in productivity. So depending on the soil condition its necessary to define segments of the bucket.

Patel et al. [1] has estimated bucket capacity, digging forces according to SAE standard. He developed the generalized breakout force model and digging force. Forces acting at each joint of bucket are calculated by static force analysis. Patel et al. [2] discussed about principles of soil mechanics. Also estimated resistive force calculation according to earth-moving equation. Bennett et al. [3] discussed about soil tool interaction forces mainly separation and penetration force. For separation force and penetration force analytical model has been derived by author. In their paper, they have given detailed information about penetration resistance and separation resistance. Also, they have modeled the bucket in the software and simulated it against soil, by giving soil tool interaction and find the resistive forces. Patel et al. [4] talk over about analytical approach to calculate excavation forces and their application. In this paper, resistive force calculation are done with the help of Mckyes and Zeng models and comparison of results of both the models are given in graphical format for no of different variables. Lomate et al. [5] did shape optimization of JCB Bucket. Author have compared three designs of the bucket their angles and the shape. Calculated bucket capacity, digging force. Also, He analyzed the bucket in ANSYS 15 by giving $1 / 3$ offset and full offset as a boundary condition. Mahesh Babu et al. [6] has did the static and fatigue analysis of excavator bucket with excavator under maximum breakout condition. Tupkaret et al. [7] done the analysis of excavator digger and estimated the Stress developed at the bucket tip. Patel [8] focuses on optimization of different parts of backhoe link mechanism for reducing weight and shape optimization. Sarkar and Rakesh et al. [9] has done a study on excavator bucket to find its strength. Rahul Mishra et al. [10] estimated the procedure to calculate digging force and bucket volume. Nishane et al. [11]. In this paper he model the bucket in CAD software. The existing bucket is made with the help of two different materials such as EN 8 and HARDROX 400.Optimized bucket is made up of HARDOX 400 AND 500 material. FEA is done in ANSYS software and various results are found out. Patel et al. [12] has attentive to solid modeling of hydraulic excavator, and FEA is done to evaluate the strength. Singh et al. [13] has discussed about the soil tool interaction behavior of the earthmover bucket. Maciejewski et al. [14] has done the experimentation to find the most efficient tool trajectories and tool shape for heavy machines during filling process of the tool [15].

\section{Force Calculation for Bucket}

\section{Digging force calculation}

Digging force is nothing but force required to dig the terrain. These forces are exerted at the tip of the bucket. Digging forces are classified

*Corresponding author: Dey T, Department of Mechanical Engineering, D.Y. Patil College of Engineering, Akurdi, Pune, India, Tel: +91 20 27653058; Fax: +9120 27653057; E-mail: tapobrata.dey@gmail.com

Received August 01, 2017; Accepted August 28, 2017; Published August 31 2017

Citation: Khedkar Y, Dey T, Padasalagi Y (2017) Study of Forces Acting on Excavator Bucket While Digging. J Appl Mech Eng 6: 282. doi: 10.4172/21689873.1000282

Copyright: @ 2017 Khedkar Y, et al. This is an open-access article distributed under the terms of the Creative Commons Attribution License, which permits unrestricted use, distribution, and reproduction in any medium, provided the original author and source are credited. 
into bucket curling force and arm curling force. Bucket curling force is the force generated at the tip of the bucket due to bucket cylinder and arm crowd force is the force generated at the tip of the bucket due to arm cylinder. Generally digging force is calculated at maximum breakout condition of the linkages. Maximum breakout condition is the condition at which the excavator generates maximum digging force. Total three standards are available to calculate digging force one of which is SAE standard. According to SAE J1179 digging forces for maximum breakout condition is shown in Figure $1[16,17]$.

In this $\mathrm{d}_{\mathrm{A}}, \mathrm{d}_{\mathrm{E}}, \mathrm{d}_{\mathrm{F}}, \mathrm{d}_{\mathrm{D}}, \mathrm{d}_{\mathrm{C}}$ are the distances and $\mathrm{F}_{\mathrm{B}}$ and $\mathrm{F}_{\mathrm{S}}$ are the bucket curling force and arm curling force. Bucket curling force is tangent to tip radius of bucket and it's generated by bucket cylinder. It's given by,

$$
\mathrm{F}_{\mathrm{B}}=\frac{\mathrm{p} \times\left(\frac{\pi}{4}\right) \times \mathrm{D}_{\mathrm{B}^{2}} \times \mathrm{d}_{\mathrm{A}} \times \mathrm{d}_{\mathrm{C}}}{\mathrm{d}_{\mathrm{D}} \times \mathrm{d}_{\mathrm{B}}}
$$

Here $\mathrm{D}_{\mathrm{B}}$ is the diameter of the bucket cylinder, $\mathrm{p}$ is the working pressure. For our case, $d_{A}=130.8 \mathrm{~mm}, d_{E}=1197.6 \mathrm{~mm}, d_{F}=4000.5 \mathrm{~mm}$, $\mathrm{d}_{\mathrm{D}}=1394.4 \mathrm{~mm}, \mathrm{~d}_{\mathrm{C}}=450 \mathrm{~mm}, \mathrm{~d}_{\mathrm{B}}=620 \mathrm{~mm}, \mathrm{D}_{\mathrm{B}}=135 \mathrm{~mm}, \mathrm{p}=34.3$ $\mathrm{Mpa}, \mathrm{D}_{\mathrm{A}}=120 \mathrm{~mm}$. After putting all the values,

$$
\mathrm{F}_{\mathrm{B}}=26.40 \mathrm{KN} \text {. }
$$

Arm crowd force is given by,

$$
\mathrm{F}_{\mathrm{S}}=\frac{\mathrm{p} \times\left(\frac{\pi}{4}\right) \times \mathrm{D}_{\mathrm{A}^{2}} \times \mathrm{d}_{\mathrm{E}}}{\mathrm{d}_{\mathrm{F}}}
$$

Here $\mathrm{D}_{\mathrm{A}}$ is the diameter of the arm cylinder.

Arm crowd force $\left(\mathrm{F}_{\mathrm{S}}\right)$ is $146.95 \mathrm{KN}$

For easy operation of the bucket it's necessary that the digging force must be greater than the resistive force offered by soil.

\section{Resistive force calculation}

Resistive force is the force offered by the soil to the bucket during its movement into the soil. Before discussing about resistive force, we should know about the digging modes. To get more convincing result the excavator digging operation is splits into three modes digging mode I, II and III.

Digging mode I: This mode includes the penetration of bucket into soil. Bucket teeth's and the toe plate are the two parts which comes in contact with the soil during this mode. This mode is referred as penetration mode.

Digging mode II: After penetration bucket goes deep into soil so other parts such as some part of toe plate and back plate come in contact with the soil. This mode is referred as separation mode.

Digging mode III: This is the escape mode. In this mode, the bucket comes out of the ground. So, the re-curling force is the main factor in this mode to move the bucket out of the soil.

When excavator is performing its operation the first part which comes in contact with the soil is the bucket. As it's a soil tool interaction soil offers large amount of resistive force to the bucket. The interaction of soil and bucket is depending upon soil properties and bucket parameters. Below table shows the parameters which affect the soil and bucket interaction (Table 1).

Other than this the resistive force is depends upon Shape of Terrain, Soil Conditions, Tool Parameters etc.

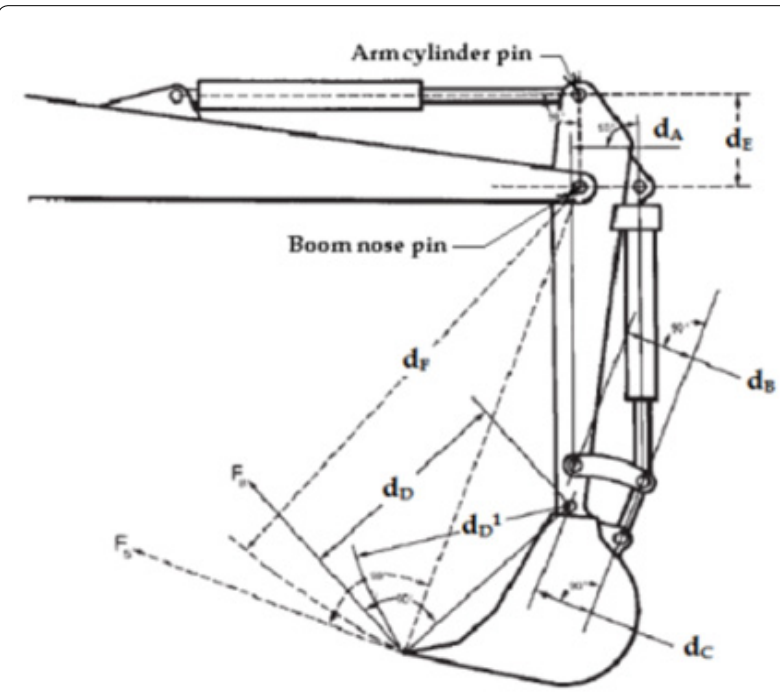

Figure 1: Maximum digging force calculations.

\begin{tabular}{|c|c|c|c|}
\hline Parameters & $\begin{array}{c}\text { Penetration } \\
\text { Resistance }\end{array}$ & $\begin{array}{c}\text { Separation } \\
\text { Resistance }\end{array}$ & Combined \\
\hline $\begin{array}{c}\text { Rack Angle } \\
\text { the soil }\end{array}$ & $\checkmark$ & $\checkmark$ & $\checkmark$ \\
\hline $\begin{array}{c}\text { Friction Between } \\
\text { Soil And Bucket }\end{array}$ & $\checkmark$ & $\checkmark$ & $\checkmark$ \\
\hline $\begin{array}{c}\text { Angle of soil-soil } \\
\text { Friction }\end{array}$ & $\checkmark$ & $\checkmark$ & $\checkmark$ \\
\hline $\begin{array}{c}\text { Initial Angle Of Soil } \\
\text { Friction }\end{array}$ & $\checkmark$ & $\checkmark$ & $\checkmark$ \\
\hline Tooth Semi Angle & $\checkmark$ & $\checkmark$ & $\checkmark$ \\
\hline Soil Cohesion & $\checkmark$ & $\checkmark$ & $\checkmark$ \\
\hline Soil Adhesion & $\checkmark$ & $\checkmark$ & $\checkmark$ \\
\hline $\begin{array}{c}\text { Soil Cohesion- } \\
\text { Adhesion }\end{array}$ & $\checkmark$ & $\checkmark$ & $\checkmark$ \\
\hline No of Teeth & $\checkmark$ & $\checkmark$ & $\checkmark$ \\
\hline Soil Normal \\
Pressure
\end{tabular}

Table 1: Parameters affecting resistive force.

\section{Penetration resistance}

Penetration resistance is the resistance offered by soil for penetration of bucket into soil. During penetration bucket teeth and toe plate are the two parts which comes in contact with the soil so for calculation purpose these two parameters are considered. Resistive force offered by soil to the tooth and toe plate is different so we need to consider these two forces separately. The addition of these two forces leads to total resistive force offered by soil during penetration.

Total Penetration Resistance $=$ Resistance From tooth + Resistance from separation plate (Toe Plate).

Resistance from Separation Plate,

$\mathrm{R}_{\mathrm{ps}}=\left(\mathrm{q}_{\mathrm{s}}, \mathrm{A}_{\mathrm{s}}\right)=\left(\mathrm{c}_{\mathrm{a}}+\mathrm{p}_{\mathrm{n}} \tan \delta\right) \cdot \mathrm{A}_{\mathrm{s}}=17.84 \mathrm{KN}$

Resistance from Bucket Tooth,

$\mathrm{R}_{\mathrm{pt}}=\mathrm{n} \cdot \mathrm{q}_{\mathrm{t}} \cdot \mathrm{A}_{\mathrm{t}}=\mathrm{n} \cdot\left[\mathrm{p}+\left(\mathrm{c}_{\mathrm{a}}+\mathrm{p} \cdot \tan \delta\right) \cdot \cot \alpha\right] \cdot \mathrm{A}_{\mathrm{t}}=1.05 \mathrm{KN}$

Total Penetration Resistance $=18.89 \mathrm{KN}$ 
Citation: Khedkar Y, Dey T, Padasalagi Y (2017) Study of Forces Acting on Excavator Bucket While Digging. J Appl Mech Eng 6: 282. doi: 10.4172/2168-9873.1000282

\section{Separation resistance}

After penetration bucket is moving inside the soil other parts of the bucket such as back plate and some part of the toe plate come in contact with the soil and it will create resistance to motion of the bucket into soil. Because of these reasons this resistance needs to be calculated for easy movement of the bucket into the soil. Figures 2 and 3 shows all the forces acting on the bucket during digging mode II. After doing summation of all horizontal and vertical forces we get total resistance offered by this triangular wedge as,

$$
\mathrm{R}(\mathrm{S})=\frac{\begin{array}{c}
-A D F \cdot \cos (\beta+\rho+\delta)+W \cdot \sin (\alpha+\rho+\ddot{O})+C F 1 \cdot \cos \Phi \\
+2 A C F \cdot \cos \Phi+2 \cdot S F 2 \cdot \cos \Phi
\end{array}}{\operatorname{Sin}(\beta+\rho+\delta+\Phi)}
$$

Putting all the values, Total separation resistance is come out to be $95.55 \mathrm{KN}$.

\section{FEE Model (Fundamental Earth Moving Equation)}

Reece in 1965 gave a generalized Fundamental Equation for Earthmoving operations popularly known as an FEE. With the help of FEE and Modified FEE we can find out resistive force at horizontal and uneven surface. One advantage of this model is that we can find out the remolding force of the bucket. If we add total remolding force into total resistive force of the bucket we get total resistive force in complete cycle. Terrain profile is even.

When bucket is inserted into soil many forces are acting on the bucket or tool as shown in Figure 4. Here d is the depth below soil, Lf is length of failure surface, and $\mathrm{R}$ is force resisting movement of wedge.

Fundamental earth moving equation is,

$$
\mathrm{F}=\left(\gamma g \mathrm{~d}^{2} \mathrm{~N}_{\gamma}+\mathrm{cdN}_{\mathrm{c}}+\mathrm{qdN}_{\mathrm{q}}\right) \mathrm{w}
$$

Gravitational force acting on the bucket is given by,

$$
\mathrm{F}_{\mathrm{g}}=\mathrm{V}_{\mathrm{s}} \cdot \gamma \cdot \mathrm{g}
$$

The remolding force $\left(\mathrm{F}_{\mathrm{r}}\right)$ is,

$$
\mathrm{F}_{\mathrm{r}}=\mathrm{V}_{\mathrm{r}} \cdot \gamma \cdot \mathrm{g} \cdot \mathrm{d}
$$

The total resistive force is the sum of the resistive force at bucket and the remolding force.

Here $\mathrm{N}_{\gamma}, \mathrm{N}_{\mathrm{c}}, \mathrm{N}_{\mathrm{q}}$ are constants,

$$
\begin{aligned}
& \mathrm{N} \gamma=\frac{\cot \rho+\cot \beta}{2[\cos (\rho+\delta)+\sin (\rho+\delta) \cot (\beta+\Phi)]} \\
& \mathrm{Nc}=\frac{1+\cot \beta \cdot \cot (\beta+\Phi)}{[\cos (\rho+\delta)+\sin (\rho+\delta) \cot (\beta+\Phi)]} \\
& \mathrm{Nq}=\frac{\cot \rho+\cot \beta}{[\cos (\rho+\delta)+\sin (\rho+\delta) \cot (\beta+\Phi)]}
\end{aligned}
$$

The value for each parameter is listed below,

Density of soil $(\gamma)=1900 \mathrm{Kg} / \mathrm{m}^{3}$

Gravity $(\mathrm{g})=9.8 \mathrm{~m} / \mathrm{s}^{2}$

Tool depth below the soil $(\mathrm{d})=1.2 \mathrm{~m}$

Soil cohesion $(\mathrm{c})=25000 \mathrm{~N} / \mathrm{m}^{2}$

Width of bucket $(\mathrm{w})=0.919 \mathrm{~m}$

Struck Volume $\left(\mathrm{V}_{\mathrm{s}}\right)=0.493 \mathrm{~m}^{3}$

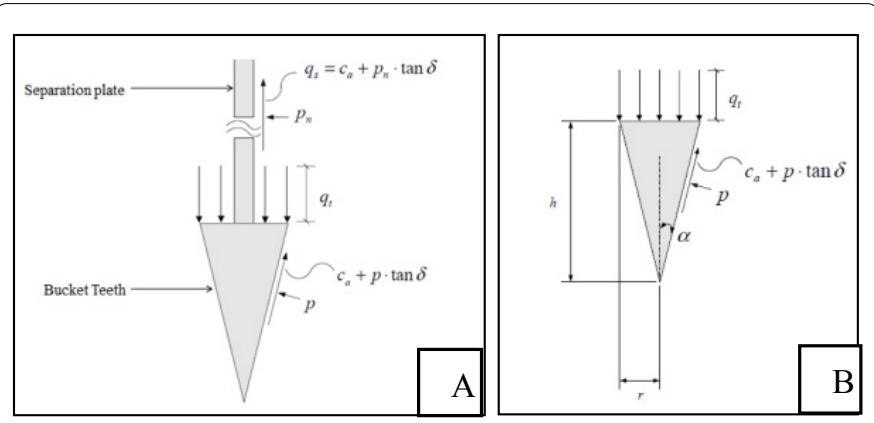

Figure 2: Forces acting on teeth of bucket.
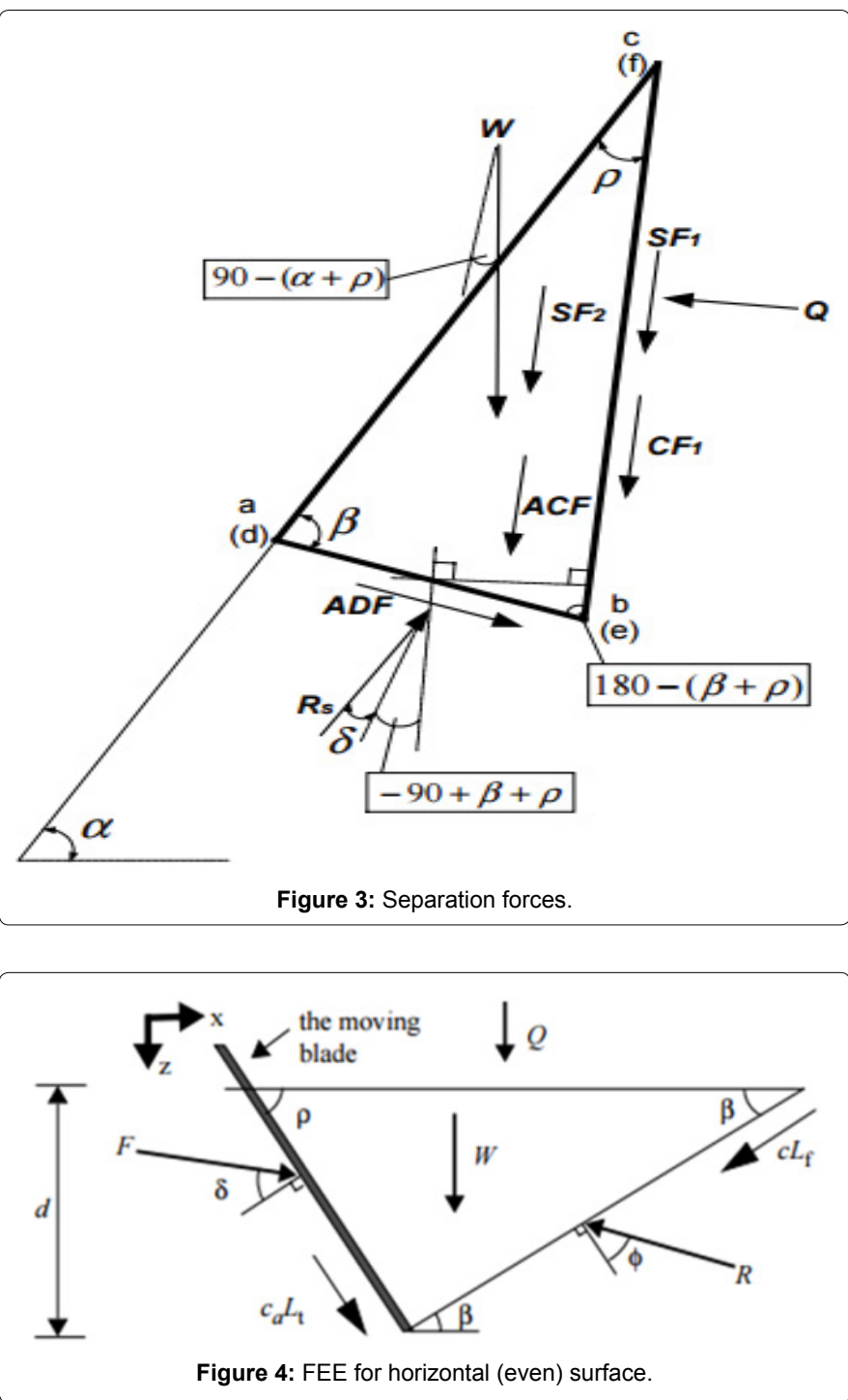

Heaped capacity $\left(\mathrm{V}_{\mathrm{R}}\right)=0.63 \mathrm{~m}^{3}$

Surcharge Pressure $(q)=10 \mathrm{~N} / \mathrm{m}^{2}$

Rack angle $(\rho)=35^{\circ}$

Friction angle between material and blade $(\delta)=20^{\circ}$

Soil-soil friction angle $(\varnothing)=30^{\circ}$ 
Citation: Khedkar Y, Dey T, Padasalagi Y (2017) Study of Forces Acting on Excavator Bucket While Digging. J Appl Mech Eng 6: 282. doi: 10.4172/2168-9873.1000282

Soil failure wedge angle $(\beta)=37^{\circ}$

The resistive force $\left(\mathrm{R}_{\mathrm{s}}\right)$ is $88.55 \mathrm{KN}$

Terrain Profile is uneven (Modified FEE)

The first model has been modified because it was only for horizontal surface but during digging we don't know about the surface condition whether it's horizontal (even) or uneven surface. So the new model for uneven surface is developed.

The various forces acting on tool is shown in Figure 5. After summing all the vertical and horizontal forces we get total resistive force as:

$$
\begin{aligned}
& \mathrm{F}_{\mathrm{s}}=\mathrm{d}^{2} \cdot \mathrm{w} \cdot \gamma \cdot \mathrm{g} \cdot \mathrm{N}_{\mathrm{w}}+\mathrm{c} \cdot \mathrm{w} \cdot \mathrm{N}_{\mathrm{c}}+\mathrm{V}_{\mathrm{s}} \cdot \gamma \cdot \mathrm{g}\left(\mathrm{N}_{\mathrm{q}}-1\right) \\
& \mathrm{N} \gamma=\frac{(\cot \beta-\tan \alpha) \times(\cos \alpha+\sin \alpha \cdot \cot (\beta+\Phi))}{2[\cos (\rho+\delta)+\sin (\rho+\delta) \cot (\beta+\Phi)]} \\
& \mathrm{Nc}=\frac{1+\cot \beta \cdot \cot (\beta+\Phi)}{[\cos (\rho+\delta)+\sin (\rho+\delta) \cot (\beta+\Phi)]} \\
& \mathrm{Nq}=\frac{\cot \rho+\cot \beta}{[\cos (\rho+\delta)+\sin (\rho+\delta) \cot (\beta+\Phi)]}
\end{aligned}
$$

This force must be added into total remolding force to get total resistive force for uneven surface.

After putting all the values in above formulas, we get,

Total resistive force for uneven surface $=71.68 \mathrm{KN}$

Study has been carried out to know the effect of parameters such as bucket depth below the soil, rack angle, bucket width, and inclination of surface on resistive force. For even and uneven surface graphs are plotted for different parameter to know the effect of the resistive force. Blue color line is for uneven surface and red color line is for even surface.

From graphs, it's clear that as the bucket depth below the soil increases soil resistive force also increases except for inclination of the surface. Also for increase in rack angle and bucket width resistive force also increases. So, optimum value of these parameters must be selected while designing to get less resistance force (Figures 6-9).

\section{Force acting at joints of bucket}

Static force analysis of bucket is carried out to know forces coming at the pin joints under the maximum breakout force condition and during lifting of bucket to know the pin failure or to design the pin of the bucket. Figure 10a shows the bucket under maximum breakout condition. The digging force is acting at an angle of $22.4^{\circ}$ at the bucket tip.

Figure 10b shows the forces acting at different joints calculated

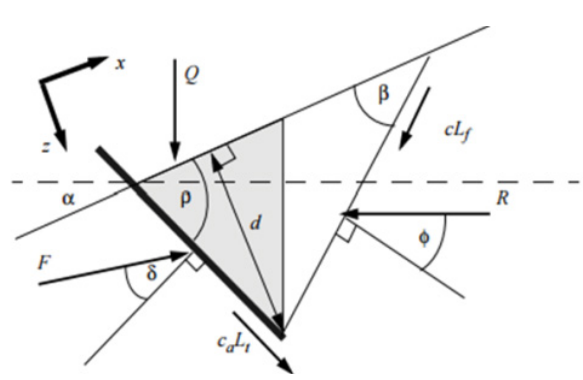

Figure 5: Modified FEE for uneven surface.

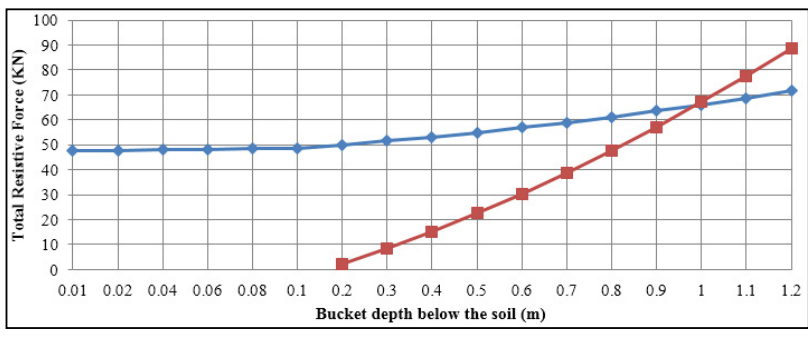

Figure 6: Effect of bucket depth below the soil on total resistive force.

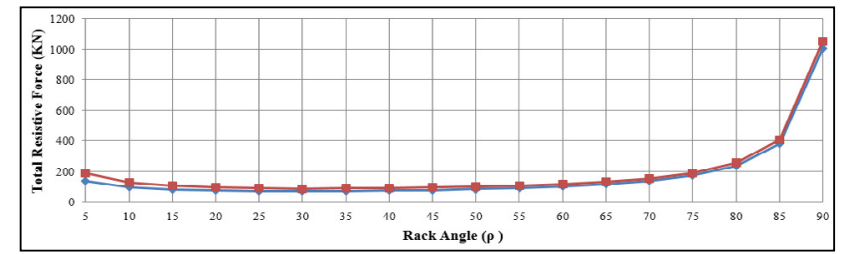

Figure 7: Effect of rack angle on total resistive force.

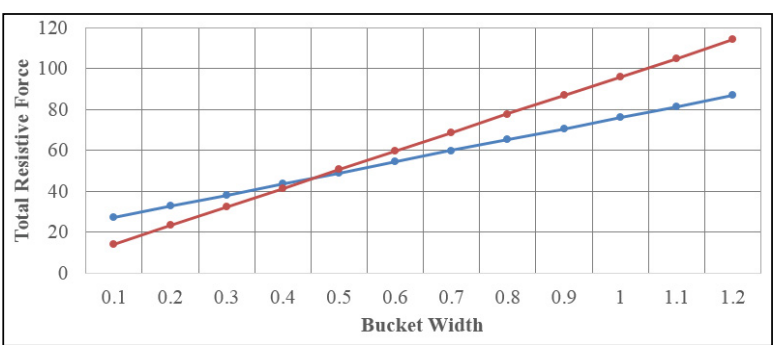

Figure 8: Effect of bucket width on total resistive force.

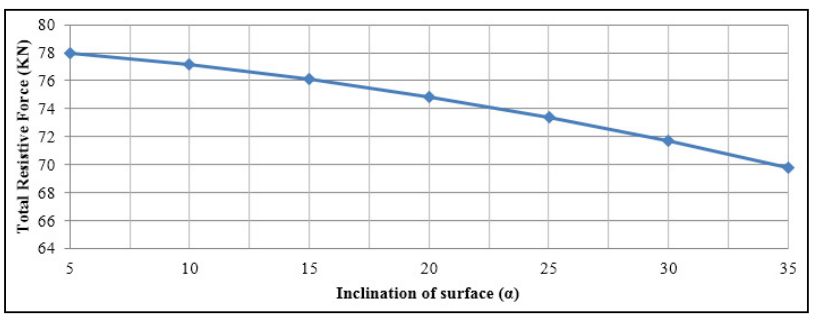

Figure 9: Effect of surface inclination on total resistive force.

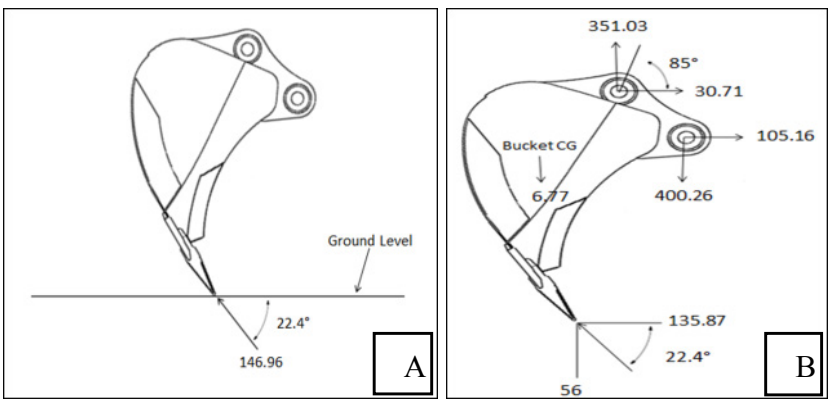

Figure 10: Static force analysis under max breakout condition. 
Citation: Khedkar Y, Dey T, Padasalagi Y (2017) Study of Forces Acting on Excavator Bucket While Digging. J Appl Mech Eng 6: 282. doi: 10.4172/2168-9873.1000282

Page 5 of 6

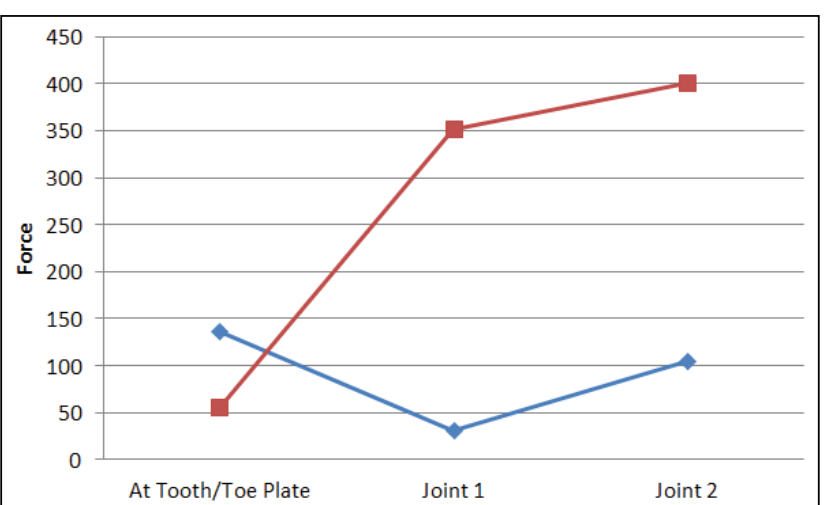

Figure 11: Forces acting at each joint under max breakout condition.

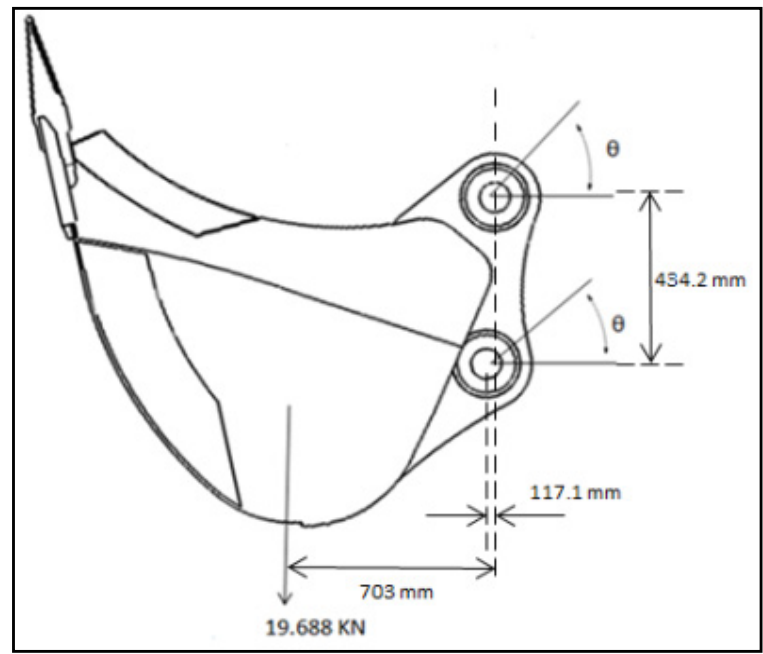

Figure 12: Forces acting at each joint under lifting condition.

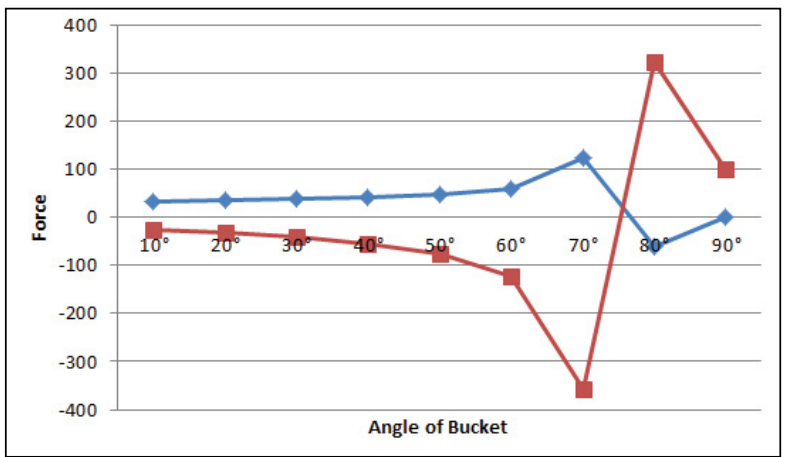

Figure 13: Forces acting at each joint 1 under max breakout condition during lifting.

by using mechanics rules. These forces are graphically represented in Figures 11 and 12 show the forces acting at each joint during lifting of bucket.

Following Graph shows the force acting at the upper and lower pin joint. It shows horizontal and vertical component of force for different

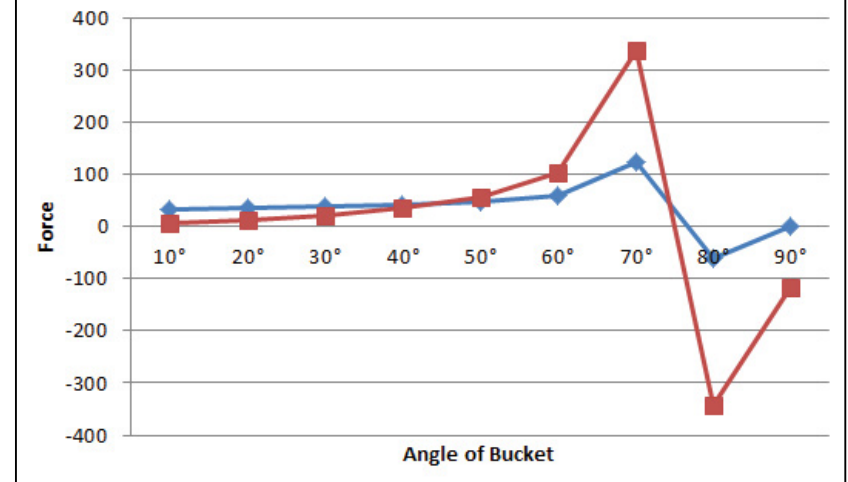

Figure 14: Forces acting at each joint 2 under max breakout condition during lifting.

angles. Negative and positive values of the forces show the direction of the forces (Figures 13 and 14).

\section{Conclusion}

Analytical soil-tool interaction models are utilized to calculate resistive forces exerted during digging operations. The digging force is higher than the resistive force so the bucket design is proficient for digging. From the graphs, it's clear that resistive force is increasing as the tool depth below the soil, bucket width and rack angle so it's necessary to select optimum value of bucket width and rack angle while designing bucket. With the static force analysis, we come to know about forces acting at joints of the bucket for each angle of lift and dig.

\section{References}

1. Patel BP, Prajapati JM (2012) Evaluation of bucket capacity, digging force calculations and static force analysis of mini hydraulic backhoe excavator Machine design 4: 59-66.

2. Patel BP, Prajapati JM (2012) Evaluation of resistive force using principle of soil mechanics for mini hydraulic backhoe excavator. Int $\mathrm{J}$ Machine Learning and Computing 2.

3. Bennett N, Walawalkar A, Heck M, Schindler C (2016) Integration of digging forces in a multi-body-system model of an excavator. J Multi-Body Dynamics 230.

4. Patel BP, Prajapati JM, Gadhvi BJ (2011) An excavation force calculations and applications: An Analytical Approach. Int J Eng Sci and Tech 1: 2.

5. Lomate S, Biradar S, Dhumal K, Waychal A (2016) Design and shape optimization of excavator bucket. IRJET.

6. Mahesh Babu P, Sreenivas K (2014) Fatigue analysis and design optimization of a digger arm Int Journal of Mech Eng and robotics Res.

7. Tupkar MP, Zaveri SR (2015) Design and analysis of an excavator bucket. Int Jo Sci Res Eng \& Tech.

8. Patel BP, Prajapati JM (2012) Structural optimization of mini hydraulic backhoe excavator attachment using FEA approach, IJMERR.

9. Sarkar M, Shaw RK, Ghosh SK (2015) Numerical analysis of stresses in mine excavator bucket. J Mining Science 51: 309-313.

10. Mishra R, Dewangan V (2013) Optimization of component of excavator bucket IJSRET 2: 076-078.

11. Nishane SS, Kongre SC, Pakhare KA (2016) Modeling and static analysis of Backhoe excavator bucket. Int J Res in Advent Tech.

12. Patel BP, Prajapati JM (2012) Static analysis of mini hydraulic backhoe excavator attachment using FEA approach. IJMERR.

13. Singh S, Cannon H (1998) Modeling and identification of soil-tool interaction in automated excavation. IEEE/RSJ Int Conference on Intelligent Robotic Systems. 
Citation: Khedkar Y, Dey T, Padasalagi Y (2017) Study of Forces Acting on Excavator Bucket While Digging. J Appl Mech Eng 6: 282. doi: 10.4172/2168-9873.1000282

Page 6 of 6

14. Maciejewski J, Jarcebowski A, Trampezynski W (2013) Study on efficiency of the digging process using the method of excavator bucket, Elsevier, The Netherlands.

15. Patel BP, Prajapati JM (2011) Soil-tool interaction as a review for digging operation of mini hydraulic excavator. IJEST.
16. ISO (2007) Earth-moving machinery-Volumetric ratings for hoe-type and grabtype buckets of hydraulic excavators and backhoe loaders - ISO 7451:2007.

17. SAE International (1990) Hydraulic, excavator and backhoe digging forces. 400 Common wealth Drive, Warrendale, PA. 